\title{
INFORMATION STANDARDS QUARTERLY
}

\author{
WINTER 2010 | VOL 22 | ISSUE 1 | ISSN $1041-0031$
}

SPECIAL EDITION: STATE OF THE STANDARDS AND YEAR IN REVIEW

PLANNED OBSOLESCENCE:

A NEW MODEL FOR

ACADEMIC PUBLISHING

DCMI: BEYOND THE

ELEMENT SET

E-BOOKS: THE ETERNAL

NEXT BIG THING

Z39.7 LIBRARY METRICS \& STATISTICS DATA DICTIONARY 
[OPINION ]

A judgment formed about something;

a personal view, attitude, or appraisal

\title{
E-books: The Eternal Next Big Thing
}

\author{
Back in 2002, the organizers of the Frankfurt Book Fair granted "new media" \\ purveyors their own hall. Entering this space was something of a sensory onslaught, \\ with light and sound coming from every direction. Some of the largest and fanciest \\ stands presented the new wave of e-book readers, which were being hyped in \\ the tech press as the new way to read. At one of the stands-Cytale's, as I recall-a \\ young French woman pressed one of the devices into my hands. It did not impress \\ me. It was dull looking, reacted slowly, and had access to a tiny sliver of content.
}

Anyone with even a passing knowledge of e-book technology knows that that generation of e-book readers passed quickly into the night having made barely a dent in the collective consciousness of even the technically obsessed. Some dreams, however, never die, and so it is with e-books and their reading devices. We are currently experiencing what one could label the second wave of e-book enthusiasm (or third, depending on your perspective), a wave largely driven by the might and reach of Amazon and Sony and their ability to push their devices onto the world stage.

E-books are, of course, nothing particularly new. Some would date them back to 1971, when Michael Hart sat down at a mainframe terminal and keyed in the American Declaration of Independence. With the development and emergence of the CD-ROM in the 1980s, e-books became available to a wider audience, albeit typically through schools and libraries and other such institutions due to the hardware and media costs. It took a globally available and attractive data delivery platform (aka the Web) to bring e-books, or more broadly electronic texts, into the public consciousness. In the 1990s, efforts such as Project Gutenberg, the Electronic Text Center at the University of Virginia, and many others brought e-books into the mainstream, although the idea of having texts available online has always seemed more attractive than actually reading them.

Anyone working in libraries knows that many publishers have been offering thousands of titles as webbased e-books for a number of years, dating back to the appearance of netLibrary around the turn of the century. There has been steady development in this area, with some major publishers (e.g., Springer) taking the lead

CONTINUED»

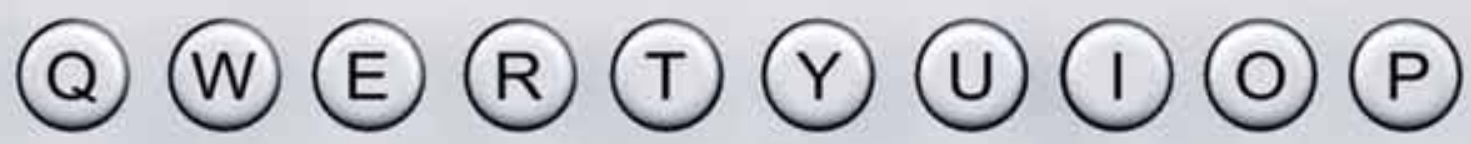



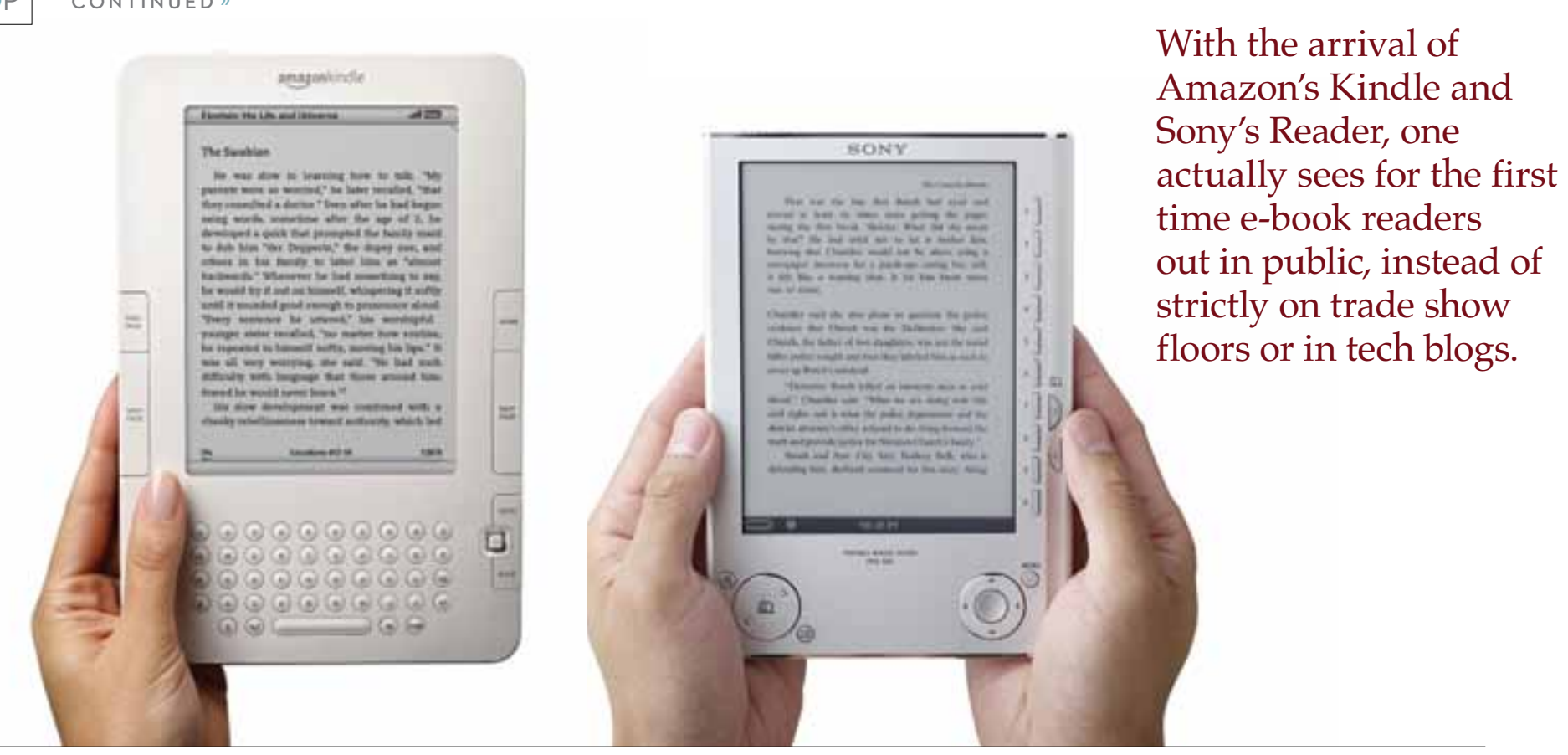

on making titles available electronically. These e-books have yet, however, to find broad and unflinching acceptance among readers, and one could debate whether this is due to technical (poor display and printing options), cultural (one prefers a book in the hand), and/or other reasons. It bears noting that these products are largely scientific literature from academic and scholarly publishers, thus there is a fairly defined boundary between them and the general public market for books.

The launch of Amazon's Kindle and Sony's Reader has pushed the e-book hype to new heights in the last two years. Amazon, in typically cryptic fashion, claims that the recent Christmas season was a clear breakthrough for the Kindle and Kindle Books, although given what Amazon has riding on this investment, one would expect such hyperbole. Sony is somewhat quieter than Amazon, but their sheer global reach forces one to take notice of their Reader line. With the arrival of these two lines one actually sees for the first time e-book readers out in public, instead of strictly on trade show floors or in tech blogs. That would seem to indicate that some sort of tipping point has been reached, but one would be wise to heed the cautionary lesson provided by PDAs-omnipresent in 2002, co-opted by cell phones, all but gone todaybefore getting too excited about all of this hubbub.

What is holding everyone back from embracing e-books and their reading devices? There is likely no single reason for the hesitancy, although one often hears some form of the comment "the technology just isn't ripe yet." Such a statement is typically an amalgam of various factors, only some of which are technical in nature. One reason to reject e-books is that reading from backlit monitors is stressful for our eyes. Virtually all reader devices these days use nonbacklit e-ink technology, which solves the backlighting problem, but e-ink is not a panacea for screen readability issues. (Do not try to use the device in a low light setting.) Then there are the formatting issues. Compared to the clean and tidy layout of even the simplest book, pages on screens and readers are all over the place in terms of spacing and font size; fonts at small size pixelate horribly, which our eye notices even if we consciously do not. The lack of color and moving images in the current generation of readers flies in the face of what is otherwise a colorful and multimedia landscape. Last, but certainly not least, the readers are for all practical purposes single-use devices.
Given how much even a basic cell phone can do these days, that is a glaring weakness of the technology.

Even if one disregards the technical issues, there are a host of psychosocial reasons perhaps slowing the adoption of e-books and readers. For one, many people associate reading with moments and spaces where we shut out the outside world; technological devices tend to bring that world back into our view even unbidden. As many have observed, the wholly different haptic experience of a reader in the hand is a poor substitute for the substantiality (and usability) of a printed book, a factor that even the technophilic often admit. On a more practical note, it takes time and energy to manage any technology, which is time spent not reading nor enjoying the device. While many readers are quite facile with software and external drives, not all are.

Cost considerations also play a role. Compared to technologies such as cell phones and iPhones/iPods, e-book readers are rather expensive (not least when one considers the aforementioned one-dimensionality). As with any device, the lifespan is limited, and then there are the inherent fragility and theft issues to consider. (Would you take your reader 
to a beach? A pool?) Depending on one's reading habits, it is questionable whether the cost of the device amortizes well across many books, or represents a major surcharge on a book's price. When it comes to content, no one really seems to know what e-books should cost. Amazon arbitrarily set the price of many bestsellers at $\$ 9.99$, but this has recently come under direct attack from publishers and even before that prices within their catalog varied dramatically for reasons not always clear to consumers. Regardless of the cost of the title, in the end the consumer only has a digital file of limited utility and longevity, which is the tip of the iceberg in terms of consumer rights issues.

It is perhaps this category more than the others-i.e. copyright and digital rights management-that shackles the development of the market. While there is currently an explosion of hardware devices on the market-one would think given the number of choices that everyone has or desires a reader-there has not been a similar explosion on the content side. Certainly, Amazon can point to 300,000+ titles in its Kindle storearguably the largest collection of e-books available-but upon closer inspection, one notices that beyond the bestsellers and mass market fiction lurks a vast collection of vanity or at least less-thanprofessionally published material. This boosts the numbers, but does not satisfy the reading needs of even a moderately adventurous and broad reader.

Why the dearth of content? One word: copyright. Publishers are keen to avoid what they perceive as the mistakes made by the music industry, and are preemptively taking measures to thwart piracy, even though many will point out that a book and a song are two very different media entities. What this means is that traditional copyright issues-such as the lack of global licensing, making content inaccessible for those sitting in the wrong country, and digital piracyhave led to a fragmented e-book market where standards and interoperability are left out. There are already various e-book formats, and while a crafty user can get around many of them to reformat a file (but who really does this on a daily basis?), publishers are also grasping at the usual digital rights management (DRM) tactics of encoding and copy protecting to thwart piracy. This makes it impossible for consumers to manage their e-book library as they choose, even within the legal confines of copyright, where reformatting and self-archiving are ostensibly permitted practices in most nations. None of this is consumer friendly, and what it means in practical terms is that content available for one device may well be unavailable for the next. This limits consumer choice and makes a hassle out of what should be a pleasant and enjoyable experience.

This is the great paradox: we have a whole wave of new and much ballyhooed readers coming on to the market, but every last one of them pales in comparison to a smart device such as an Android phone or an iAnything, and the content choices are severely restricted, even for Kindle shoppers. This combination of lack of broad functionality (one can't even send an e-mail from most readers) and dearth of content would seem to put the readers in a precarious situation with the public. It does not take much imagination to predict that of the readers currently on the market, only a handful will survive, and even for those one could question the ultimate impact they will have. As Apple rolls out the iPad in the coming months, and if it enjoys even a portion of the success that the iPod and iPhone have found, this could all happen sooner than we might think.

To this point, I have attempted to capture the current thoughts and trends swirling around e-books and readers. I can also report from personal experience with both an Amazon Kindle and a Sony PRS-600 Touch Reader, having recently purchased one of each for student projects at the university in Germany where I am currently teaching. As a librarian (we love books, right?) and a generally technically adept person often accused of being a geek, I assumed that

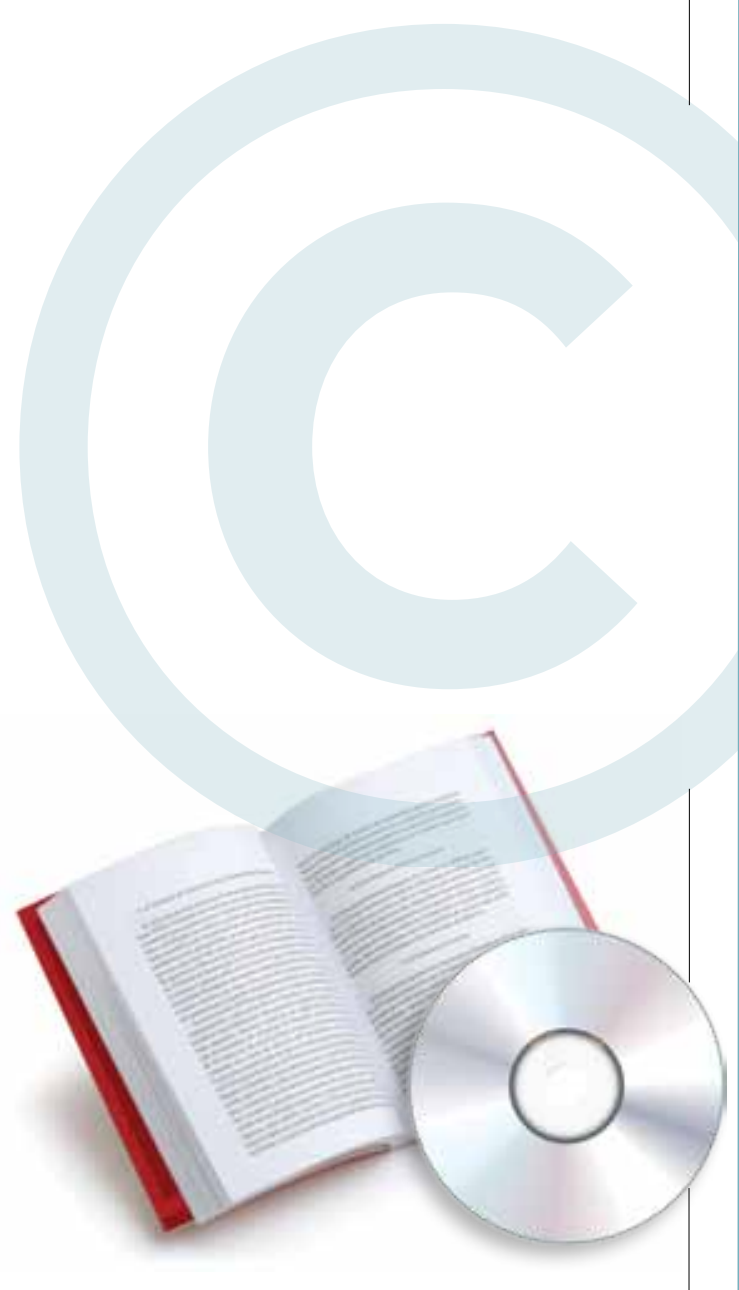

\section{Why the dearth of content? One word: copyright.}

Publishers are keen to avoid what they perceive as the mistakes made by the music industry, and are preemptively taking measures to thwart piracy, even though many will point out that a book and a song are two very different media entities. 
I would find the devices irresistible and would need to order my own for personal use. Nothing could be further from the truth. While I see some benefits-many books on one device, low battery usage, light weight-these are more than offset by the negatives. These include never being able to find the books I actually want to read and constant frustration with a primitive device that feels much more like my Handspring Visor Deluxe circa 2002 than my iPod Touch in 2010. Then there are the myriad DRM issues, which offend the librarian in me and turn buying and managing my "books" into a morass of fine print and time spent trolling through forums looking for ways to reformat files.

It seems a foregone conclusion that the trend toward reading digital texts in some fashion will only continue to build over time. In hindsight, we will likely regard the current situation as a part of that development, but I find it unlikely that we are experiencing the seminal moment with regard to the establishment of e-books, although the recent introduction of the Apple iPad and the iBookstore certainly raises the profile and stakes of the game. Already one hears talk of the new device as a Kindle killer, and while that remains to be seen, the wild success of the iPhone should strike fear into e-reader competitors. On the other hand, Apple has struggled with DRM issues with iTunes, and all of those nasty and complex international rights issues cannot be mellifluously talked away by Steve Jobs. The day will come when the rights holders make owning and managing digital reading content palatable and painless. Fixing those issues will be far more challenging than developing flashy hardware, even one with a beautiful display and that coveted logo. | OP | doi: 10.3789/isqv22n1.201005

DALE ASKEY <daskey@k-state.edu>, library, is currently Visiting Professor Electronic Publishing and Multimedia at Fakultät Medien, HTWK-Leipzig Lebenslauf in Germany. View his blog at: htwkbk.wordpress.com/. normally located in Kansas in an academic
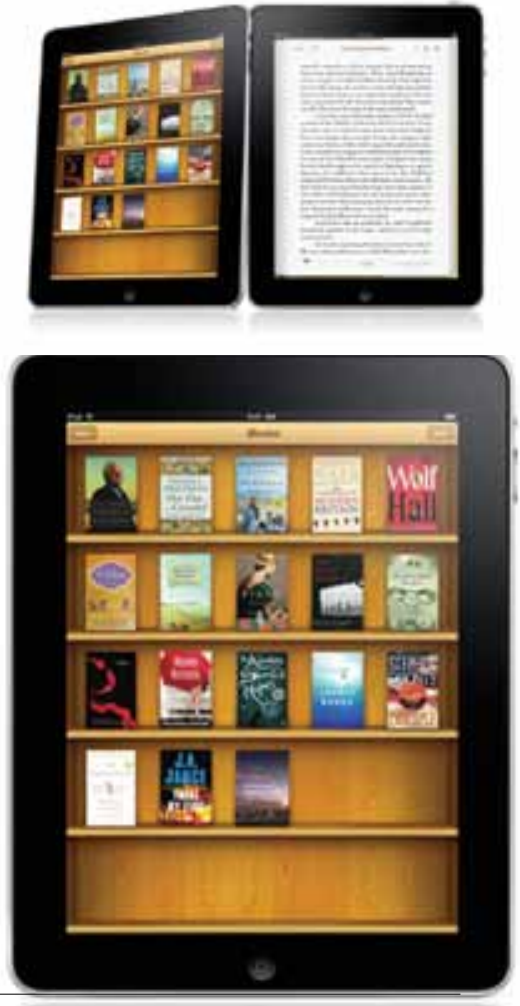

\section{The recent introduction of the Apple iPad and the iBookstore certainly raises the profile and stakes of the game. Already one hears talk of the new device as a Kindle killer, and while that remains to be seen, the wild success of the iPhone should strike fear into e-reader competitors.}

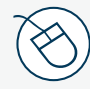

\section{Amazon Kindle \\ www.amazon.com/kindle/}

\section{RELEVANT} LINKS

Apple iPad

www.apple.com/ipad/
The Electronic Text Center at the University of Virginia etext.virginia.edu

Frankfurt Book Fair www.buchmesse.de/en/

Hart, Michael. Gutenberg: The History and

Philosophy of Project Gutenberg. August 1992. www.gutenberg.org/wiki/Gutenberg:The_History_and Philosophy_of_Project_Gutenberg_by_Michael_Hart
netLibrary

www.netlibrary.com

Paul, Ian. Amazon: Kindle Is Most Gifted Item Ever. PCWorld, December 28, 2009

www.pcworld.com/article/185508/amazon_kindle_is_most_ gifted_item_ever.html

Project Gutenberg

www.gutenberg.org 